Abstracta Iranica

Revue bibliographique pour le domaine irano-aryen

Volume 34-35-36 | 2017

Comptes rendus des publications de 2011-2013

\title{
Denise Aigle. L'intégration des Mongols dans le rêve eschatologique médiéval
}

\section{Thomas Tanase}

\section{(2) OpenEdition \\ 1 Journals}

Édition électronique

URL : http://journals.openedition.org/abstractairanica/41815

DOI : $10.4000 /$ abstractairanica.41815

ISSN : 1961-960X

\section{Éditeur :}

CNRS (UMR 7528 Mondes iraniens et indiens), Éditions de l'IFRI

\section{Référence électronique}

Thomas Tanase, "Denise Aigle. L'intégration des Mongols dans le rêve eschatologique médiéval ", Abstracta Iranica [En ligne], Volume 34-35-36 | 2017, document 2, mis en ligne le 30 décembre 2016, consulté le 26 septembre 2020. URL : http://journals.openedition.org/abstractairanica/41815 ; DOI : https://doi.org/10.4000/abstractairanica.41815

\section{Ce document a été généré automatiquement le 26 septembre 2020}

Tous droits réservés 


\title{
Denise Aigle. L'intégration des Mongols dans le rêve eschatologique médiéval
}

\author{
Thomas Tanase
}

\section{RÉFÉRENCE}

Denise Aigle. «L'intégration des Mongols dans le rêve eschatologique médiéval », in : D. Aigle, I. Charleux, V. Goossaaert et R. Hamayon, éds., Miscellanea Asiatica. Mélanges en l'honneur de Françoise Aubin. Saint-Augustin, Institut Monumenta Serica, 2010, p. 683-717.

Dans cette étude détaillée d'une quarantaine de pages, D. Aigle s'intéresse à la question du Prêtre Jean, relue à travers la confrontation avec les sources islamiques. La victoire du chef des Qara Kitai sur le sultan seldjoukide Sanjar en 1141 fut à l'origine des premiers bruits sur le Prêtre Jean dans les sources latines. L'A. rappelle la montée au pouvoir de Gengis Khan pour passer ensuite à l'attaque mongole sur l'Europe. En réaction, les premiers missionnaires partent vers les terres mongoles, Jean de Plan Carpin, Ascelin de Crémone et André de Longjumeau, puis, une dizaine d'années plus tard, Guillaume de Rubrouck. Après ce rappel historique, D. Aigle analyse et compare un grand nombre de sources occidentales et orientales. Les récits présentent un certain nombre de points communs. Les Mongols n'ont pas de chef, ils élisent Gengis Khan, il marche contre le Prêtre Jean et le défait. Le récit de Plan Carpin est à cet égard original. À partir d'éléments remontant au Roman d'Alexandre entendus sur place, il fait du Prêtre Jean un roi indien ayant résisté à Gengis Khan. Toutefois, c'est le schéma faisant du Prêtre Jean un roi de la steppe défait par Gengis Khan qui va s'imposer par la suite, et ce dès Simon de Saint-Quentin. Cette vision des faits tire son origine de la défaite face à Gengis Khan du souverain des Kereit, To'oril, et du chef des Naiman, Küchlüg. Par la suite, ces deux personnages ont fini par être confondus dans les sources. On retrouve cette confusion chez l'historien syriaque Bar Hebraeus, preuve de l'origine orientale 
des premiers récits sur le Prêtre Jean. Enfin, vers la fin du XIII ${ }^{e}$ s., la figure du Prêtre Jean devient de plus en plus littéraire, chez Jean de Joinville et Marco Polo, qui rapportent la prise de pouvoir de Gengis Khan de manière positive. Le lien entre les différentes versions vient sans doute du fait que les récits circulaient chez les Mongols, comme en témoigne l'historien arménien, Héthoum de Korikos. Il attribue à Gengis Khan une mission salvatrice. Il est celui qui doit faire la reconquête des territoires repris aux Croisé par les musulmans. Et c'est ici que l'A. fait une comparaison décisive avec les récits de 'Ațā' Malik Juvaynī et leur diffusion dans les sources chrétiennes orientales pour nous montrer l'origine commune de ces différentes légendes qui ont fini par donner la version latine d'un Gengis Khan, soutenu par le Dieu chrétien, contre le Prêtre Jean. Le langage eschatologique commun à l'islam et à l'Occident a permis des allers-retours entre les deux cultures. Chacune a réélaboré ce fonds commun de traditions autour de Gog et Magog et des peuples de la fin des temps pour donner un sens à l'irruption des peuples de la steppe. En Occident, les invasions mongoles ont donné naissance à la légende du Prêtre Jean - et à la transformation de ce dernier en un mauvais souverain, chrétien oriental, vaincu par un Gengis Khan guidé par Dieu, et dont on attendait la conversion (ou du moins celle de son peuple).

\section{AUTEURS}

THOMAS TANASE

CNRS - UMR 8167 « Orient et Méditerranée » 